\title{
The missing elements of the noncommunicable diseases action plan
}

$\mathrm{N}$ o money. No targets. No consensus on controversial issues such as guaranteeing access to affordable drugs, stiffened measures against the tobacco and alcohol industries, and regulations to curb international trade in unhealthy products.

It seems the United Nations' (UN) newly minted political declaration on noncommunicable diseases (NCDs), including cardiovascular diseases, cancer, diabetes and chronic pulmonary disease, has no shortage of flaws.

The declaration calls on the UN General Assembly's 193 member states to draw up voluntary national plans to tackle NCDs and commits the World Health Organization (WHO) to establishing a global surveillance network and a set of global targets before the end of 2012 to monitor trends and report progress in the bid to reduce death and disability from NCDs (www .un.org/en/ga/ncdmeeting2011/pdf/NCD _draft_political_declaration.pdf).

Yet, leaders from many developing nations and a few rich countries such as Norway and Finland said they had hoped for a much tougher plan to fight NCDs, complete with hard targets for improved health outcomes, action to curb controversial trade practices and financial commitments from international aid donors.

"Non-communicable diseases should receive the attention they deserve in the development agenda" and are currently inadequately supported through official development assistance (ODA), Dr. Eduardo Bustos Villar, secretary of the determinants of health and health relations for the ministry of health of Argentina told the High-Level Meeting on the Prevention and Control of Noncommunicable Diseases on behalf of the Group of 77 nations and China. "Despite the importance of NCDs for public health and their growing burden on national health systems, it should be noted that NCDs account for less than $1 \%$ of official development assistance

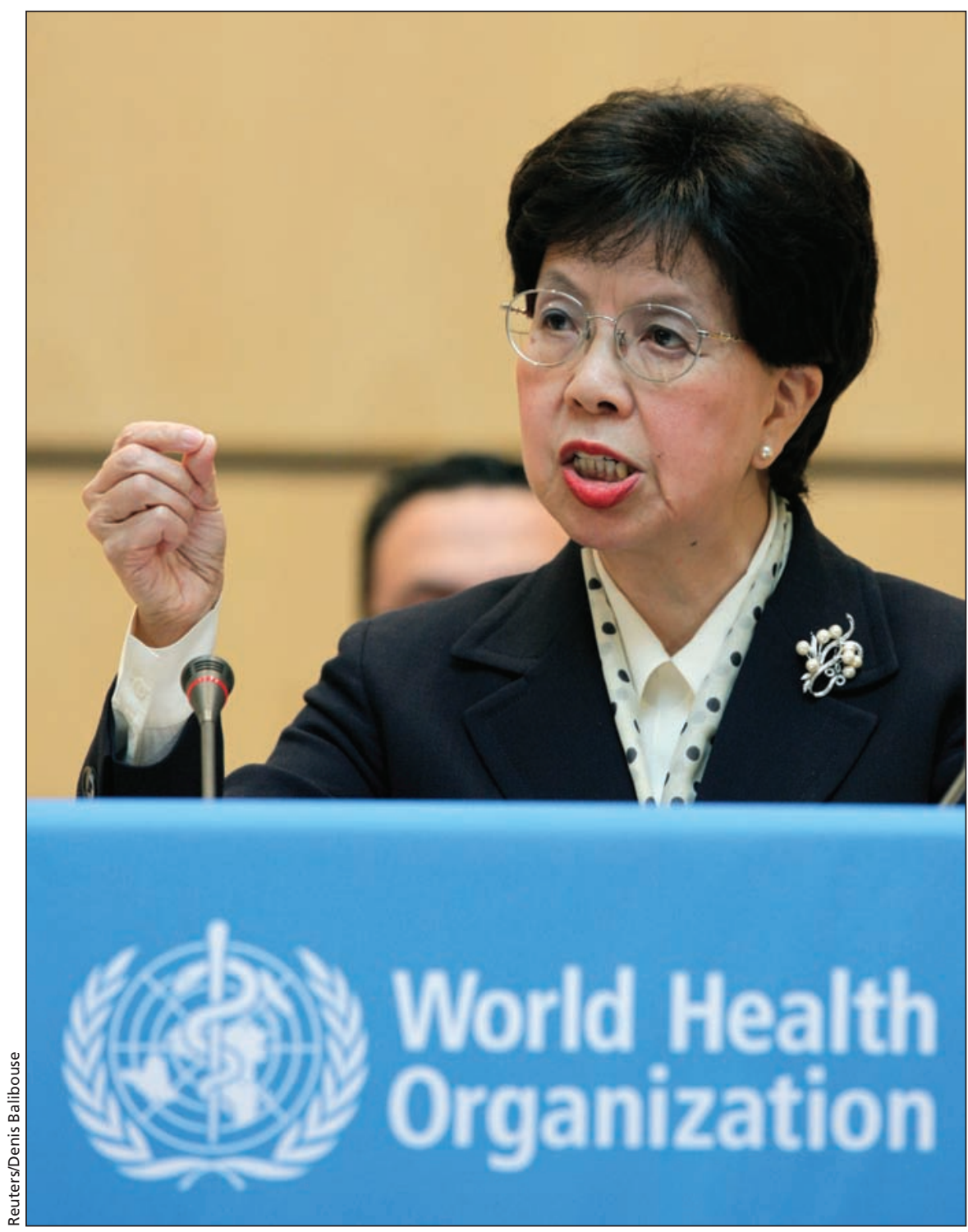

"Countries cannot treat their way out of NCDs. Prevention is crucial," World Health Organization Director-General Dr. Margaret Chan told the High-Level Meeting on the Prevention and Control of Non-communicable Diseases held in New York City, NY.

for health. The G77 and China calls for the fulfilment of all ODA-related commitments, including the commitment by many developed countries to achieve the target of 0.7 per cent of gross national income for ODA by 2015" (www.g77.org/nc/).

Villar also argued that developing nations need flexible international trade laws in order to gain access to generic drugs.

Nassir Abdulaziz Al-Nasser, president of the 66th session of the UN General Assembly, argued that the "public health pendulum has swung too far" in favour of a few infectious diseases at the expense of NCDs, which, worldwide, kill a higher number of people - 
36 million per year — and account for $60 \%$ of global mortality. The UN must now consider the next steps in tackling NCDs in the run-up to a formal review of the declaration in 2014, he said.

Several health administrators, political leaders and international health experts pressed for immediate action, with many calling for NCDs to be included when the Millenium Development Goals are revised and relaunched in 2015.

WHO Director-General Dr. Margaret Chan told a session on international cooperation in confronting NCDs that pharmaceutical firms will have to curb their profit expectations to distinguish between "reasonable profits" and "greed."

Chan also called on member states to stand fast against legal challenges by the tobacco industry aimed at undermining domestic tobacco regulations. "Even an old dog can learn some nasty new tricks."

Because the cost is so high, "countries cannot treat their way out of NCDs. Prevention is crucial," Chan added. To illus- trate the point, she noted that if Mexico spent the same amount per capita on controlling obesity as the United States currently does, the cost would exceed the country's total health budget.

A crucial first step in tackling NCDs will be to bolster surveillance, Chan said, noting that 65 countries representing $85 \%$ of the world's population currently do not compile statistics on the causes of mortality and have almost no data regarding risk factors for NCDs.

Other delegates, including Dr. Thomas Frieden, director of the US Centers for Disease Control and Prevention, proposed specific NCD targets. Frieden suggested that nations adopt a set of guidelines for NCD control that includes such targets and regulations as a $10 \%$ reduction in alcohol consumption; 5 gram per day limits on salt intake; a 25\% reduction in hypertension prevalence; a $25 \%$ reduction in cardiovascular disease mortality rates; a $10 \%$ reduction in diabetes prevalence; and the elimination of marketing of unhealthy foods to children.
Yet while many would have preferred the inclusion of more specific targets and measures in the declaration, even outspoken critics of the process many of whom complained that international drug and food corporations had unwarranted influence on the outcome - believe the declaration provides a solid foundation for tougher action in the future.

While the declaration "has some good provisions on breastfeeding and eliminating marketing of food high in sugar, fat and salt to children ... timebound targets are absent," notes Indrani Thuraisingham, head of the Consumers International (a world federation of 220 consumer groups in 115 countries) regional office for Asia Pacific and the Middle East. "Ultimately, the summit should lead member states to truly effective solutions rather than weak voluntary industry pledges," she says. - Paul Christopher Webster, New York City, NY

CMAJ 2011. DOI:10.1503/cmaj.109-4011 